\title{
SABERES EM DIÁLOGO NA PRÁTICA FILOLÓGICA EDITORIAL
}

\section{DIALOGUE OF KNOWLEDGE IN THE EDITORIAL PHILOLOGICAL PRAXIS}

\author{
Rosa Borges* \\ Universidade Federal da Bahia, Salvador, BA, Brasil
}

Resumo: Delineamos o fazer filológico na contemporaneidade, a partir das práticas editorais e da crítica filológica que tomam por objeto o texto teatral censurado, em seus aspectos material, social e cultural. Para ilustrar a práxis fillóǵgica que realizamos, tomamos Quincas Berro d'Água, novela de Jorge Amado adaptada para o teatro por João Augusto, considerando os materiais constituintes do dossiê da referida peça de teatro, para esboçar uma proposta editorial que leve em conta os saberes em diálogo no campo da Filologia e as abordagens críticas, textual, genética e sociológica.

Palavras-chave: filologia; crítica textual; critica genética; sociologia dos textos; prótica editorial.

Abstract: We delineate the philological work in the contemporary world based on the editorial practices and the philological criticism that take as object the censored theatrical text, in its material, social and cultural aspects. To illustrate the philological praxis we have carried out, we take Quincas Berro d'Água, a Jorge Amado novel adapted by João Augusto for the theater, considering the materials that form the dossier of the aforementioned play, to outline an editorial proposal that takes into account the dialogue of knowledge in the Philology field and critical, textual, genetic and sociological approaches.

Keywords: Philology; Textual Criticism; Genetic Criticism; Sociology of Texts; Editorial Practice.

* Universidade Federal da Bahia - UFBA, Salvador, BA, Brasil; borgesrosa66@gmail.com 
Linha D'Água (Online), São Paulo, v. 31, n. 2, p. 7-27, maio-ago. 2018

\section{Palavras iniciais}

$\mathrm{Na}$ Universidade Federal da Bahia, os estudos filológicos se realizam em duas linhas de pesquisa, uma que pertence ao Programa de Pós-Graduação em Língua e Cultura, Filologia Textual, e outra, ao Programa de Pós-Graduação em Literatura e Cultura, Crítica e Processos de Criação em Diversas Linguagens. Em nossos estudos, realizamos aproximações entre campos disciplinares diversos, o que nos faz rever e, ao mesmo tempo, atualizar a prática de edição de textos. Assim, a Crítica Textual, a Crítica Genética, a Bibliografia Material ou Textual, a Sociologia dos Textos, entre outras, estão em diálogo constante em nossa investigação filológica.

Nosso objetivo é discutir a práxis filológica contemporânea, propondo uma metodologia editorial para tratamento do texto teatral censurado e de outros textos a ele relacionados, quais sejam: matérias de jornal, pareceres censórios, certificados de censura, entrevistas, entre outros. Estamos organizando o arquivo digital com os acervos dos dramaturgos baianos ou que produziram na Bahia, o qual será futuramente disponibilizado no site www.textoecensura.ufba.br, trazendo os textos dramáticos encenados no contexto da ditadura militar e, em parte, a documentação paratextual (matérias e críticas de jornal, documentação censória) referentes à cena teatral baiana.

O texto teatral censurado foi a motivação para repensar e renovar a prática de edição de textos, conforme o exercício das críticas: textual, genética e sociológica. Para ilustrar nossas ações filológicas, tomamos Quincas Berro d'Água, uma novela de Jorge Amado, adaptada para o teatro por João Augusto.

\section{Filologia como crítica textual}

No lugar teórico da Filologia, o texto é investigado como objeto material que traz um conjunto de "[...] propriedades físicas, visuais, gráficas, semióticas e estéticas próprias [...] que participam da construção do sentido" (GRÉSILLON, 2009, p. 41) e que engendram na prática editorial as leituras e os estudos variados. A Filologia, da forma como a fazemos, é, portanto,

[...] como um feixe de práticas de leitura, interpretação e edição que, a um só tempo, consideram como objeto, de modo indissociável, língua, texto e cultura. 
Tem por objetivo a compreensão e estudo dos processos (i) de produção das práticas de cultura escrita; (ii) de transmissão histórica dos textos; (iii) de circulação social do texto, (iii) recepção e reconfigurações que uma dada época constrói para o texto (McKENZIE, 2005). Como nenhuma dessas perspectivas pode ser pensada sem considerar a implicação dos sujeitos envolvidos com tais tarefas, a Crítica Textual considera, ainda, os processos de "mediação editorial" (CHARTIER, 2002b) de todos os atores envolvidos com o processo de produção, leitura, impressão e circulação. De toda essa configuração, podem resultar diferentes produtos que, obviamente, dependerão do intento de cada pesquisador e de sua relação com o objeto (BORGES; SOUZA, 2012, p.21, grifo dos autores).

Rita Marquilhas (2010), ao glosar o termo filologia, define seus limites. Escreve ela: Filologia é o

[e]studo do texto escrito na perspectiva de sua produção material, da sua transmissão através do tempo e da sua edição. [...] O termo evoluiu de uma acepção muito lata, romântica sobretudo, que englobava estudos literários e linguísticos, para o conceito estrito de disciplina concentrada na recriação das coordenadas materiais e culturais que presidiram à fabricação e sobrevivência de um texto escrito. A orientação última é a de preparar a edição do texto, daí que a flologia culmine na crítica textual. Tem ainda, como disciplinas auxiliares, a codicologia, a bibliografia material, a manuscriptologia e a paleografia, segundo as quais se descreve e interpreta a dimensão material do texto: o livro, o documento e a letra que o enformam (Carlos CEIA (coord.). s. v. "Filologia". E-Dicionário de Termos Literários. <http://www.edtl.com.pt>, consultado em 20 set. 2012).

A Crítica Textual se ocupa do processo histórico em duas vertentes: a do texto em processo de produção, que envolve o autor e seu trabalho com os manuscritos, e a do texto em processo de transmissão, que considera a existência ou a ausência do original e a tradição dele derivada, com destaque para os suportes que fazem circular o texto. A Crítica Textual desenvolve metodologias próprias para preservação, reconstituição e leituras dos textos, sendo aplicada a textos antigos e medievais, modernos e contemporâneos, situação que a distingue em duas modalidades: Crítica Textual Tradicional (filologia do manuscrito ausente: textos antigos e medievais), Crítica Textual Moderna (filologia do manuscrito presente: textos modernos e contemporâneos). 
Considerando a perspectiva da produção textual e, somada a essa, a perspectiva da recepção, a partir da ação dos mediadores do processo de transmissão e de edição, outras modalidades se apresentam: a Crítica Textual Genética e a Crítica Textual em perspectiva Sociológica (Sociologia dos Textos), respectivamente. Suas práticas põem em questão as edições realizadas, sobretudo a edição crítica, suas aplicações e finalidades, ao tempo em que esclarecem os produtos editoriais como ajustes à metodologia empregada, em concordância com as situações textuais investigadas.

Do exercício da Crítica Textual, apresentam-se diferentes propostas de edição, conforme os materiais disponíveis para estudo e intenção do pesquisador, a saber:
a. uma edição fac-similada;
b. uma edição diplomática;
c. uma edição interpretativa;
d. uma edição sinóptico-crítica;
e. uma edição crítica;
f. uma edição crítico-genética ou crítica em perspectiva genética;
g. uma edição genética;
h. uma edição histórico-crítica;
i. uma edição eletrônica.

Devemos ressaltar, porém, que toda edição é crítica. A opção pela forma de edição dos textos far-se-á de acordo com os propósitos do investigador e a singularidade do material selecionado. Além disso, os produtos editoriais poderão ser apresentados em suporte papel ou eletrônico.

O exercício do labor filológico, conforme situações textuais encontradas, comuns à tradição, à época e ao lugar em que os textos se inscrevem, tem exigido uma atenção especial para os textos dramáticos. São comumente textos escritos a várias mãos, e que, partindo-se de seu processo de produção até uma possível publicação, recepção e circulação, tomam rumos diferentes, seja do "palco à página" ou da "página ao palco" (expressões empregadas por Chartier (2002)). Desse modo, trabalhar com tais textos requer, do filólogo textual, certos cuidados para selecionar o texto de base, aquele que deverá representar não o texto mais próximo do original 
Linha D'Água (Online), São Paulo, v. 31, n. 2, p. 7-27, maio-ago. 2018

(arquétipo), mas o texto autorizado, escolhido conforme critérios filológicos estabelecidos, e, a partir de então, de acordo com os procedimentos adotados, fixar o texto crítico, que será disponibilizado para diversos fins, se for este o propósito do editor, ou ainda evidenciar, por meio de outros modelos editoriais, a pluralidade de textos, em confronto sinóptico, dar a ler os demais textos que transmitem a obra. Salientemos ainda que a pesquisa de fontes tem-se mostrado de grande importância para o trabalho filológico. Assim, críticas, comentários, citações, traduções, adaptações, são considerados na leitura e interpretação do texto a ser editado.

Para a conservação e preservação dos textos trabalhados, e também para torná -los acessíveis a outros interessados, propomos a digitalização dos mesmos. Devido ao avanço tecnológico, temos optado pela edição fac-similar ou a simples reprodução fotográfica, transferindo tal material para o meio digital, organizando um Banco de Textos. No que tange à Filologia Textual, partindo das diversas configurações e reconfigurações de texto, entendido como definitivo, acabado, inacabado, múltiplo, variável, repensa-se a teoria filológica. Nesse momento, conciliam-se os campos do saber da Filologia, da Genética e da Sociologia dos Textos, interessando-se, respectivamente, pelo produto (texto final), pelo processo (prototexto) e pelos atores sociais que deixam marcas na produção, reprodução e publicação dos textos (escritor, autor, copista, censor, revisor, editor...).

McKenzie, conforme Chartier (2005, p.11), converte a bibliografia no "[...] estudio de la sociología de los textos"(MCKENZIE, 2005, p.31) e define a Sociologia dos Textos, como disciplina "[...] que estudia los textos como formas registradas, así como los procesos de su transmisión, incluyendo su producción y su recepción [...]” (MCKENZIE, 2005, p. 30), ocupando-se de todas as formas de texto, evidenciando que as formas repercutem no significado. Com isto, rasura a divisão tradicional entre ciências da descrição e ciências da interpretação, entre morfologia e hermenêutica, além de rever também o lugar da biblioteca para consultar os textos em suas diferentes materialidades (CHARTIER, 2005). As reflexões postas por McKenzie (1985/1986), titular da cátedra de Crítica Textual em 1987 em Oxford, ao publicar, em 1986, o livro Bibliography and the sociology of texts, resultado de três conferências, as Panizzi Lectures, de 1985, traduzido para francês (1991), italiano (1999) e 
Linha D'Água (Online), São Paulo, v. 31, n. 2, p. 7-27, maio-ago. 2018

espanhol (2005), transformaram a ciência bibliográfica (bibliografia analítica ou descritiva), a crítica textual e a história da leitura (CHARTIER, 2005).

$\mathrm{Na}$ teoria sociológica,

[...] o texto é entendido não como produto de uma intenção autoral, mas de aspectos colaborativos, contextos históricos, pessoais, intertextuais, caracterizados, eles próprios, pela variação. A perda de centralidade da intencionalidade final e a valorização do leitor e da leitura como espaço de criação de sentido directamente associada à consciência da natureza discursiva da significação constituem um elo de ligação entre a teoria literária pós-estruturalista e a teoria social da edição, fundamentando alguns projectos editoriais electrónicos (LOURENÇO, 2009, p. 229).

Assim, a Crítica Textual, a Crítica Genética e a Sociologia dos Textos (Crítica Sociológica) são lugares que se entrecruzam na investigação filológica contemporânea no que se refere ao estudo das obras e de sua circulação. Está-se diante de uma situação em que vários agentes interferem na produção, reprodução e impressão de uma obra, de uma variedade de formas autorizadas, em que se mostra uma instabilidade textual, e de recursos provenientes das novas tecnologias que permitem aos leitores reconstruir e difundir os textos. Nesse sentido, cada versão reclama o direito de ser editada, sendo as novas tecnologias instrumentos para a apresentação e o fazer da própria edição, trazendo a história do texto, a partir das diversas abordagens críticas. Nosso trabalho caminha nessa direção.

A Filologia, através de sua principal atividade, a reconstituição de textos, tem buscado, na relação com outros campos do saber, evidenciar uma cultura que se revela por meio da materialidade e da discursividade dos textos que recupera. "[...] A filologia é, portanto, expressão essencial do conhecer, pois só filologicamente, isto é, sobre os textos, na plenitude de seu significado sensível e representativo, se conhece um autor, um discurso ou um conceito." (RIGHI, 1967 apud ARAÚJO, 1986, p. 195). Logo, para a edição de textos, bem como para a realização de leituras filológicas, pelo viés da interpretação, devemos fazer interagir, em nossas investigações, diversos campos do saber.

Nesse contexto, observamos o regresso à Filologia e um lugar próprio para ela no campo dos Estudos Literários. Segundo Said (2007, p. 82-83), 
Linha D'Água (Online), São Paulo, v. 31, n. 2, p. 7-27, maio-ago. 2018

[u]ma verdadeira leitura filológica é ativa; implica acreditar no processo da linguagem já em funcionamento nas palavras e fazer com que revele o que pode estar oculto, incompleto, mascarado ou distorcido em qualquer texto que possamos ter diante de nós. Nessa visão da linguagem, as palavras não são marcadores significantes passivos que representam despretensiosamente uma realidade mais elevada, mas antes uma parte formativa integrante da própria realidade.

Assevera ainda que a

[...] tarefa do humanista não é apenas ocupar uma posição ou um lugar, nem simplesmente pertencer a algum local, mas antes estar ao mesmo tempo por dentro e por fora das idéias e valores circulantes que estão em debate na nossa sociedade, na sociedade de alguma outra pessoa ou na sociedade do outro (SAID, 2007, p. 101).

É, portanto, fazendo essa leitura filológica, que pretendemos, tomando-se os textos teatrais produzidos e/ou encenados na Bahia no período da ditadura militar e que revelam aspectos culturais da Bahia, aclarar como se fará a crítica filológica que busca conciliar campos teóricos distintos, como a Filologia com a Lexicologia, estudando o vocabulário, com a Análise de Discurso, com foco para o interdiscurso, a memória, a escrita feminina, por exemplo, com a História Cultural, explorando os aspectos, como história, memória e literatura, com a Crítica Genética ou de Processo, estudando o processo de criação de uma obra, com a Sociologia dos Textos, para analisar a ação dos atores sociais envolvidos com o processo de produção, leitura, impressão e circulação de uma obra.

\section{Texto teatral na cena dos estudos filológicos}

Para os textos da dramaturgia baiana, embora ciente dos trabalhos já desenvolvidos por Teresinha Marinho e Edwaldo Cafezeiro ${ }^{1}$, no preparo de edições fidedignas nas áreas da dramaturgia brasileira e do patrimônio histórico e artístico nacional, busquei uma metodologia editorial ${ }^{2}$ que atendesse às especificidades do texto tea-

Coordenador do projeto Memória da Dramaturgia Brasileira.

2 Tal metodologia foi apresentada no trabalho Uma metodologia aplicada à edição de textos 
Linha D'Água (Online), São Paulo, v. 31, n. 2, p. 7-27, maio-ago. 2018

tral (censurado), nosso objeto de investigação, que vem se ajustando à medida que os trabalhos se realizam no nosso grupo de estudo. Foram realizadas edições críticas, interpretativas e genéticas em suporte papel e eletrônico, e também edições sinópticas e fac-similares, estas, sobretudo, em suporte eletrônico.

Tais práticas editorias e estudos crítico-filológicos podem ser consultados nos trabalhos disponibilizados no site https://repositorio.ufba.br/ri/: de Ludmila Jesus (2008; 2014), Isabela Almeida (2011; 2014), Eduardo Matos (2011; 2014), Débora de Souza (2012), Williane Corôa (2012), Mabel Mota (2012; 2017), Fabiana Correia (2013), Arivaldo Sacramento (2014), Liliam Carine Lima (2014), Carla Fagundes (2014) e Hugo Leonardo Correia (2014); no livro Edição e estudo de textos teatrais censurados na Babia: literatura, teatro e história em diálogo com a filologia, publicado em 2012, como resultado da pesquisa desenvolvida desde o ano de 2006, com capítulos dos vários integrantes da Equipe Textos Teatrais Censurados (ETTC), e no livro Edição de texto e crítica filológica, também publicado em $2012 .{ }^{3}$

Os critérios para apresentação, edição e estudo crítico dos textos estão colocados nos referidos trabalhos. Para tanto, na realização das edições e estudos dos textos teatrais, tivemos de levar em conta as particularidades do gênero teatral. Trata-se de texto muitas vezes escrito a várias mãos, inconcluso, feito para ser encenado, havendo, nitidamente, uma diferença entre texto dramático e texto cênico. A

[...] escritura teatral depara-se forçosamente com regras e critérios que não pertencem ao código escrito, mas àquele da encenação. A melhor mediação, em se tratando de escrever, aperfeiçoar e refazer um texto de teatro é a que passa por uma escritura a duas mãos, a do autor e a do diretor" (GRÉSILLON, 1995, p. 276), pelo menos.

Ainda tratando sobre a mediação, a ação de vários atores sociais nos textos produzidos, D. F. McKenzie (2005) chama a atenção para a impotência desconcertante que há na relação entre a crítica textual com as realidades da produção teatral, diz ele: "Las fuentes de un evento como éste son el dramaturgo, el director, el diseñador, el compositor, los técnicos; sus mensajes se transmiten con el cuerpo,

teatrais (SANTOS, 2008).

3 Confira Santos (2012) e Borges et al. (2012), respectivamente.

BORGES, R. Saberes em diálogo na prática filológica editorial 
la voz, el vestuario, los accesorios, el decorado, las luces [...]" (MCKENZIE, 2005, p. 65). Assim, "[t]odas las versiones implican una forma ideal que nunca se completa del todo, que sólo es percibida y expresada parcialmente por cada una de ellas" (MCKENZIE, 2005, p. 66).

Observamos então que, a cada encenação, o espetáculo propõe uma nova versão do texto e uma nova interpretação, novos sentidos são ali construídos. Diante dessa situação, surgem as perguntas: que texto editar e como editar? Como definir os documentos de gênese, quando se sabe que tais textos são, por natureza, instáveis, heterogêneos e efêmeros? No que se refere aos mediadores desse processo, como considerar a ação interventiva do autor ou autores, do diretor, do ator etc., enfim, de todos que interferem na construção desse texto? $\mathrm{Na}$ tentativa de responder a tais questões, decidimos que a edição deveria contemplar todas as versões do texto, em confronto sinóptico, de preferência em meio digital, dispondo os fac-símiles, transcrevendo cada um dos testemunhos, identificando as modificações genéticas e/ou modificações realizadas por outros agentes, para registrá-las em aparatos e interpretá-las, dando conta da história do texto, através de arquivo hipertextual (eletrônico), conforme propõe Urbina et al (2005), por meio de três categorias de edição: a fac-similar digital, a diplomática/documental e a variorum eletrônica.

Como também nos comprometemos com a divulgação da produção dramatúrgica baiana, no sentido de permitir o acesso a textos para leitura e encenação, o trabalho filológico se faz da prática das edições críticas e interpretativas, quando há a fixação de um texto crítico, acompanhado de um aparato (crítico e de notas) que possa dar conta dos lugares de variação, das alterações genéticas, dos cortes, das anotações que resultam da ação interventiva do(s) autor(es), dos colaboradores (atores, figurinistas, e outros) e dos leitores (nesse caso, os censores) que deixam na materialidade do texto suas marcas, dando ao leitor a oportunidade de conhecer a história do texto e suas transformações e, ao mesmo tempo, de ter uma versão criteriosamente apresentada para seu uso, o texto crítico, que resulta da interpretação e das escolhas do editor, no seu papel de leitor crítico, também mediador nesse/desse processo.

Vimos então que um projeto editorial passa pela escolha do público a que se destina, do estado da documentação e do número e da natureza dos testemunhos, das escolhas teóricas do editor, quanto ao estatuto do texto, de sua gênese e de sua 
sócio-história, enfim, dos meios disponíveis sobre o triplo plano: humano, material e tecnológico (HAY, 1988). "Dessa combinação complexa, todo elemento pode variar em função da obra, do autor, do país."4 (HAY, 1988, p. 94, tradução nossa).

No ano de 2012, preparamos um livro que tem o título que traduz bem nossos interesses, Edição de texto e critica filológica, sobretudo por ser ele um trabalho que nasceu com o propósito de discutir a práxis filológica na contemporaneidade, a partir das nossas investigações, buscando (re)pensar as teorias e métodos da edição, levando-se em conta os problemas afetos à edição de textos modernos e contemporâneos que exigem do filólogo uma atitude crítica, atualizada, no estudo da materialidade do texto, em seu processo de produção (pensando o manuscrito moderno e o processo de criação) e de recepção (pensando como essa obra foi lida e modificada pela ação de vários mediadores), e, principalmente, procurando situar a Filologia no presente, a Filologia que fazemos hoje, que contempla as pesquisas que vão do processo de criação aos processos de transmissão e circulação de um texto ou de uma obra.

$\mathrm{Na}$ Apresentação do livro, todos os autores assinam a proposta de Filologia que praticamos e defendemos, a saber:

[...] Filologia é, nesse sentido, termo que abarca atividades deveras distintas, mas identificadas quanto ao tratamento da palavra-texto, enquanto materialidade histórica, produzida e transmitida nas vias da cultura e da sociedade, pela mediação dos sujeitos - também históricos - que a constroem, consomem, leem e, por isso, modificam-na.

A prática filológica consiste, desse modo, [...] conforme Chartier (2002b,), em um exercício de leitura e de atualização de textos a partir da concepção de que $\mathrm{a}(\mathrm{s})$ forma(s) dos mesmos participa(m),determina(m) a construção de seus sentidos, de modo que aí se coloca a fratura entre quem lê os textos no lugar da Filologia e quem o faz em outro contexto epistemológico (BORGES; SOUZA; MATOS; ALMEIDA, 2012, p. 11).

Neste livro, foram reunidas diversas possibilidades editoriais: a edição crítica em perspectiva genética; a edição genética; a edição interpretativa (em meio

4 «Dans cette combinatoire complexe, tout élément peut varier en fonction de l'ouvre, de l'auteur, du pays.» (HAY, 1988, p. 98) 
Linha D'Água (Online), São Paulo, v. 31, n. 2, p. 7-27, maio-ago. 2018

digital) e uma proposta de edição sinóptica, acompanhadas de um exercício, que aqui denominamos de crítica filológica, uma vez que instaura seu lugar de enunciação nas e pelas materialidades em que os textos se escrevem e inscrevem. ${ }^{5} \mathrm{O}$ ato de editar o texto se constrói a partir das leituras críticas que desenvolvemos.

No livro, buscamos deixar claro o que seria essa crítica filológica, diferenciando-a de outras abordagens críticas.

[...] a crítica filológica é uma prática interpretativa que objetiva a leitura dos textos a partir das coordenadas e diretrizes histórico-culturais que os tornaram possíveis. Logo, difere-se da crítica linguística (ao menos a linguística de corpora) pelo fato de esta objetivar reflexões intra-sistêmicas ou sócio-históricas das 'estruturas' ou 'funcionamento' da língua, ainda que em sociedade; separa-se da crítica literária por não operar com a oposição material versus abstrato, binarismo pelo qual tem sido possível discutir 'textos' sem refletir ou ao menos considerar as (re)inscrições histórica nos diversos suportes do 'texto'; e configura-se a partir da leitura do 'devir' textual, entre fendas de rasuras que abrem espaço para a produção do texto, mas também do não-texto, entre atos de censura, como os que decorrem dos vários 'cortes' dos técnicos de censura do Governo Militar do Brasil.

Cada uma das atuações de sujeitos históricos diferentes na trama textual traz novidades à tessitura e demonstram intencionalidades diferentes que enriquem e atualizam as diversas produções de sentido no/do texto. [...] (BORGES; SOUZA, 2012, p.58-59).

Nessa perspectiva, o texto passa a ser compreendido como um espaço de possibilidades relacionais, como um processo que envolve o contexto no qual é produzido e se inscreve, e onde adquire sua significação (GUZMÁN GUERRA; TEJADA CALLER, 2000). Os textos “[...] se reciben como objetos culturales, como sistemas ideológicos de valores y creencias, consustanciales a la cultura en que son escritos o leídos" e "[...] hablan más o menos de acuerdo con el contexto cultural en que se inscriben sus receptores" (GUZMÁN GUERRA; TEJADA CALLER, 2000, p. 34; 35). Buscamos, pois,

5 Consultar sobre as edições apresentadas no livro, das páginas 60 a 217.

BORGES, R. Saberes em diálogo na prática filológica editorial 
Linha D'Água (Online), São Paulo, v. 31, n. 2, p. 7-27, maio-ago. 2018

[...] compreender as inter-relações entre os conteúdos produzidos historicamente no texto e os mecanismos (linguístico-discursivos) produtores de significados no texto, ou melhor, pensar a leitura do texto por meio das coordenadas línguísticodiscursivas, culturais, sócio-históricas e políticas nas quais o texto foi (re)inscrito e inseminado (BORGES; SOUZA, 2012, p. 48).

Do que dissemos, podemos concluir que a Crítica Genética e a Sociologia dos Textos afetam diretamente a Crítica Textual e suas práticas. Assim, ao editar um texto, teremos de considerar todos os aspectos de sua produção e recepção. Para ilustrar o que dissemos, trazemos aqui para apresentação de uma proposta editorial o texto teatral Quincas Berro d'Água, novela de Jorge Amado (1912-2001), A morte a morte de Quincas Berro d'Água, adaptada por João Augusto (1928-1979) para o teatro.

\subsection{O Dossiê de Quincas Berro d'Água}

Para dar a conhecer a situação a ser investigada, passaremos, inicialmente, ao dossiê de Quincas Berro d'Água, uma produção do Teatro Livre da Bahia e de Roberto Santana, que se constitui dos seguintes materiais:

a. um edital Concurso de Peças Teatrais, datado de 03 de abril de 1967;

b. um documento datilografado intitulado João Augusto criador, com emendas autógrafas, em duas folhas, escrito por Jorge Amado, com sua assinatura ao final, sobre João Augusto (esse mesmo texto abre o programa de divulgação da peça, localizado e datado: Salvador, Novembro de 1972; abaixo, o nome de Jorge Amado);

c. o programa impresso de divulgação da peça;

d. a correspondência de João Augusto: um bilhete de Jorge Amado para João Augusto, datiloscrito, assinado, localizado e datado: Salvador, 19 de outubro de 1972, trazendo, no ângulo superior esquerdo, a logomarca da Academia Brasileira; um bilhete de João Augusto para Jorge Amado, em uma folha, texto datilografado, com emendas datiloscritas, registrando-se apenas um cancelamento por riscado, à tinta; lançados, à esquerda, local e data: Salvador, 20 de outubro de 1972; 
Linha D'Água (Online), São Paulo, v. 31, n. 2, p. 7-27, maio-ago. 2018

e. seis datiloscritos: (1) incompleto (numeradas as folhas até a 57, sem o final da peça), com anotações manuscritas autógrafas, sem data; (2) outra versão datiloscrita, datada de 1972, com anotações manuscritas, talvez uma cópia de Ary Barata, que, na peça, era o cantador, "repentista, trovador popular". Este material foi doado, provavelmente, por Ary Barata, em primeiro momento, ao Banco de Textos do TCA, posteriormente, ao Núcleo de Acervo do Espaço Xisto Bahia: as anotações manuscritas possibilitam tais observações; (3) texto completo, datado de 1972, com algumas emendas feitas à mão; (4) texto completo, com anotações manuscritas não autorais, datado de 1975; dois datiloscritos (um datado de 1972 e o outro de 1975) que se encontram no Arquivo Nacional do Distrito Federal, no fundo Divisão de Censura de Diversões Públicas;

f. matérias de jornais que fizeram circular na Bahia informações sobre a peça;

g. As músicas de Quincas: documento datilografado que aborda sobre as canções que estão em um disco preparado para a encenação de Quincas;

h. algumas das composições do Quincas: datiloscritos;

i. o disco com as canções do espetáculo;

j. a documentação censória.

No bilhete de Jorge Amado a João Augusto, datado de 19 de outubro de 1972, Jorge Amado afirma enviar um texto para que João Augusto trabalhe no Quincas... Diz ele: "Use-o como melhor lhe parecer: orelha, contra-capa, prefácio. Ou jogue fora se não lhe agradar.” (AMADO, 1972, f. 1).

No documento em que Jorge Amado fala sobre João Augusto, destacamos um trecho em que se mostram os lugares diversos nos quais os atores envolvidos na produção de uma obra se constroem. Jorge Amado, apoiando-se na observação de que a adaptação de uma obra é outra criação, define os papéis dele e de João Augusto no que se refere à paternidade de Quincas. Diz ele: “[...] é o meu Quincas, não abro mão da paternidade, mas é, ao mesmo tempo, outro Quincas, o de João Augusto, cabe-lhe também a paternidade" (AMADO, [1972], f. 1, grifo nosso). Afirma, adiante, que na peça "mesclam-se minha experiência humana [a de Jorge Amado] e a de João Augusto, os meus sonhos e os dele, minha luta e a dele, minha Bahia e a dele." (AMADO, 
Linha D'Água (Online), São Paulo, v. 31, n. 2, p. 7-27, maio-ago. 2018

[1972], f. 1). Reconhece, além dele e de João Augusto, outros agentes (atores sociais) responsáveis por outro Quincas, que se realiza em uma produção coletiva, a saber: Caymmi, Fernando Lona, Gereba, Edil Pacheco, Patinhas, Roberto Santana.

Roberto Santana escreveu uma página do programa, intitulada Quincas/ De bolero, baião e samba!, e, nela, destacou os grandes nomes da música popular brasileira, aos quais Jorge Amado se referira acima: Caymmi fez Canto de Nanãa; Fernando Lona compôs o bolero Venga e Beira Mágoa; Edil Pacheco e João Augusto compuseram o samba Ensinança; Gereba e seu parceiro Patinhas fizeram o Baião do Quincas, que abre e encerra o espetáculo. Tais produções foram impressas em um compacto duplo da Philips e esteve à venda nas lojas de disco e no foyer do teatro, conforme Roberto Santana. Os intérpretes das canções foram: Canto de Nanã, MPB-4, Beira Mágoa, Nara Leão (Lado 1); Baião de Quincas, Gereba; Ensinança, Edil Pacheco; Venga/Venha, Fernando Lona (Lado 2).

Pelo exposto, observamos que autores, produtor, diretor, atores, compositores, leitores e espectadores atuam na construção do Quincas. Cada um, inclusive os críticos, seria responsável por outro Quincas, que também traria em si as marcas do Quincas de Jorge Amado e de João Augusto. Autores e leitores se fazem representar e se constituem em elementos de análise da obra. Nesses documentos, registra-se, além da troca de informações entre João Augusto e Jorge Amado, a ação de compositores e cantores da música popular brasileira, de atores, do produtor, e assim o Quincas se foi transformando e se fez resultado de uma produção coletiva, na qual vários agentes deixaram as marcas de suas intervenções.

Em 1975, Quincas Berro d'Água volta à cena, desta vez, porém, segundo o próprio João Augusto, é outro Quincas, “[a] nova versão nada tem a ver com a de 72 - a de agora está pautada no circo, na revista, na chanchada, na verborragia do baiano e na violência de tudo que nos cerca."(JOÃO AUGUSTO, [16 fev. 1976]).

Para esta situação textual examinada, apresentamos diferentes propostas que foram esboçadas em trabalho por mim apresentado em 2012, no I Congresso Internacional de Estudos Filológicos (I CIEF) e VI Seminário de Estudos Filológicos (VI SEF), e publicado no livro Filologia, Críticas e Processos de Criação. ${ }^{6}$

6 O evento e o livro (resultante da publicação das palestras e conferências) foram organizados por Célia Marques Telles e Rosa Borges dos Santos.

BORGES, R. Saberes em diálogo na prática filológica editorial 
Propomos, então, no caminho da Crítica Textual, o estabelecimento de um texto, fixado criticamente, como centro provisório, nesse caso, produto do labor editorial, nos moldes de uma edição crítica, para divulgação, leitura e encenação do texto; e uma edição que considere cada testemunho/documento, tomado em sua especificidade, situado historicamente, por meio de uma edição fac-similar, sinóptica, histórico-crítica. Nessa perspectiva, o texto crítico seria apresentado em suporte papel ou eletrônico, para fins de leitura e divulgação do Quincas, de João Augusto; e as múltiplas versões do texto, para serem lidas ou conhecidas, seriam apresentadas em suporte eletrônico, além dos resultados da investigação, tanto no que se refere à prática editorial (descrição, transcrição, edição), como às leituras críticas desenvolvidas.

No domínio da crítica genética, sugerimos que se faça uma análise interpretativa do dossiê constituído, a partir do processo de construção do texto (as referências, as composições, as versões, etc.), por meio de uma edição, nesse caso, genética ou histórico-crítica. No campo da Sociologia dos Textos, propomos a realização de uma edição crítica em perspectiva sociológica, que daria visibilidade às múltiplas versões de uma mesma obra, a partir de um confronto sinóptico, e de uma edição que se faria histórica e crítica ao mesmo tempo.

Para conciliar o exercício das críticas, textual, genética e sociológica, a melhor proposta de edição seria a eletrônica. Nesta edição, seriam disponibilizados os facsímiles da documentação reunida em nosso Arquivo Textos Teatrais Censurados $(\mathrm{ATTC})^{7}$ da produção dramatúrgica para oferecer uma leitura aproximada da materialidade dos textos, permitindo ao leitor também construir outros significados, na perspectiva do que propõe Grésillon (2007) de estudar o manuscrito, como objeto material, cultural e de conhecimento. Os seis testemunhos seriam descritos; um, dentre eles, de acordo com critérios filológicos, seria tomado como texto de base e transcrito na íntegra, enquanto os demais seriam transcritos apenas nos lugares que trazem modificações, apresentados em confronto sinóptico para estudo crítico dessas mudanças no processo de produção e de transmissão (conforme opção de elaborar uma edição crítica). Considerando as múltiplas versões do texto e seus paratextos, sugerimos ainda realizar a edição de cada testemunho, tomado

7 O ATTC resulta do trabalho desenvolvido na UFBA pelo Grupo de Edição e Estudo de Textos (GEET), Equipe Textos Teatrais Censurados (ETTC), sob minha coordenação. 
Linha D'Água (Online), São Paulo, v. 31, n. 2, p. 7-27, maio-ago. 2018

em sua especificidade, para que se possam, nos caminhos do texto, observar as marcas que traçam a trajetória do fazer textual, a história do texto e seu processo de recepção. O interesse é, portanto, por todos os textos que transmitiram a obra.

O labor filológico, porém, concretiza-se para além da apresentação da edição de textos. São os comentários, em uma abordagem hermenêutica, que costuram as leituras críticas que fazemos a partir da materialidade dos textos, avançando-se pela discursividade, atualizando os sentidos que são (re)construídos, trazendo à cena temas, como: os sujeitos arquivados, os sujeitos - autor, escritor e leitor - que se constroem no arquivo e nos textos, respectivamente; os bastidores da criação e editoriais; os eventos sociais e históricos que se materializam na construção do texto; os efeitos da censura nos textos e na sociedade (contexto sócio-histórico), entre outros.

\section{Considerações finais}

No estudo da obra literária, a crítica textual é, ao lado de outros, um dos métodos de análise, como se vê em Métodos críticos para a análise literária ${ }^{8}$ (BERGEZ et al., 1997) ${ }^{9}$, que leva em conta a construção do texto e de seus sentidos na e pela materialidade. Quanto ao filólogo estudioso de textos literários, afirma Picchio (1979, p. 216-217):

[...] ele encara todas as técnicas hermenêuticas num mesmo plano, reservando-se de utilizar uma ou outra (ou uma e outra), só depois de uma escolha contingente em vista do alvo imediato a alcançar, os olhos postos sempre naquele fim último que é entendimento de um facto histórico (incluindo aí um acto de criação), dentro de um contexto determinado.

A interpretação, mais que um processo mental, é um comportamento, uma atitude do pesquisador. Esclarece Picchio (1979) que, no processo de reconstrução, o filólogo considera o texto como documento, e, dele, retirará as informações necessárias à sua interpretação, considerando, para tanto, sua experiência e cultura.

8 Este livro foi publicado originalmente em francês, em 1990, com o título Introduction aux méthodes critiques pour l'analyse littéraire.

9 Capítulo desenvolvido por Gisèle Valency. 
Linha D'Água (Online), São Paulo, v. 31, n. 2, p. 7-27, maio-ago. 2018

Remetendo para Foucault (1966), no capítulo III, Representar, de As palavras e as coisas, Picchio (1979, p. 234) conclui:

Filólogo é aquele que não considera intransponível o espaço entre um e outro epistema, coisa a que geralmente nos induz a mentalidade estruturalista [...]. Filólogo é quem, utilizando todos os instrumentos dos quais pode dispor, estudando todos os documentos se esforça por penetrar no epistema que decidiu estudar, procurar a voz dos textos e de um passado que já não considera sufocado pelos estratos sobrepostos.

No livro Edição de texto e crítica filológica, colocamos em evidência os assuntos aqui discutidos. Propomos uma nova atitude do filólogo ante os textos, considerando que cada texto tem sempre como suporte uma materialidade específica e uma história particular, que “[c]ada una de estas formas de 'publicación' se organiza según dispositivos propios que determinan de manera variable la producción de sentido" (CHARTIER, 2005, p. 7), sugerindo editar os textos, a partir de renovadas práticas da metodologia da Crítica Textual, conforme propósitos do pesquisador e finalidade da edição, sobretudo por meio de uma edição eletrônica de textos e da criação de arquivos hipertextuais.

A Filologia, a partir da pesquisa de fontes, reúne documentos/monumentos e, por meio de sua atividade investigativa, alinha estudos afins e suplementares sobre o objeto texto em diferentes abordagens conciliatórias que terminam por delinear o que estamos chamando de crítica filológica. Nesse sentido, no âmbito dos estudos filológicos, desenvolvemos como propostas de dissertações e teses uma prática de edição e de crítica que leva em consideração o texto em seus aspectos material, social e cultural.

\section{Referências}

ALMEIDA, Isabela Santos de. Três fios do bordado de Jurema Penna: leituras filológicas de uma dramaturgia baiana. f. 245 I1. 2011. Dissertação (Mestrado) - Instituto de Letras, Programa de Pós-Graduação em Letras e Linguística, Universidade Federal da Bahia, Salvador, 2011. 
Linha D’Água (Online), São Paulo, v. 31, n. 2, p. 7-27, maio-ago. 2018

ALMEIDA, Isabela Santos de. A critica filológica nas tessituras digitais: arquivo hipertextual e edição de textos teatrais de Jurema Penna. 2014. 321 f. 2 v. (um volume em site). Tese (Doutorado) - Instituto de Letras, Programa de Pós-Graduação em Literatura e Cultura, Universidade Federal da Bahia, Salvador, 2014.

AMADO, Jorge. [Bilhete de Jorge Amado a João Augusto]. Salvador, 19 out. 1972. 1f.

AMADO, Jorge. João Augusto criador. Datiloscrito. Salvador, [1972]. 2f. Texto de abertura do programa para divulgação da peça.

ARAÚJO, Emanuel. A Construção do livro: princípios da técnica de editoração. Prefácio de Antônio Houaiss. Rio de Janeiro: Nova Fronteira; Brasília: INL, 1986.

BERGEZ, Daniel et al. Métodos críticos para a análise literária. Tradução Olinda Maria Rodrigues Prata e Maria Ermantina Galvão G. Pereira. São Paulo: Martins Fontes, 1997.

BORGES, Rosa et al. Edição de texto e crítica filológica. Salvador: Quarteto, 2012.

BORGES, Rosa; SOUZA, Arivaldo Sacramento de. Filologia e edição de texto. In: BORGES et al. Edição de texto e crítica filológica. Salvador: Quarteto, 2012. p. 15-59.

BORGES, Rosa. A Filologia e os lugares das críticas textual, genética e sociológica: por um estudo de Quincas Berro D'Água, adaptação de João Augusto. In: TELLES, Célia Marques; SANTOS, Rosa Borges dos (Org.). Filologia, críticas e processos de criação. 2012. p. 53-67.

CHARTIER, Roger. Do palco a página: publicar teatro e ler romances na época moderna (séculos XVI-XVIII). Rio de Janeiro: Casa da Palavra, 2002.

CHARTIER, Roger. Un humanista entre dos mundos: Don McKenzie. [Prólogo]. In: MCKENZIE, D. F.. Bibliografía y sociología de los textos. Tradução Fernando Bouza. Madrid: Akal, 2005. p. 5-18.

CORÔA, Williane Silva. Edição de texto e estudo da linguagem proibida em Malandragem made in Babia, de Antonio Cerqueira. 2012. 200 f. Dissertação (Mestrado) - Instituto de Letras, Programa de Pós-Graduação em Literatura e Cultura, Universidade Federal da Bahia, Salvador, 2012.

CORREIA, Fabiana Prudente. O desabrochar de uma flor em tempos de repressão: edição e crítica filológica de Apareceu a Margarida de Roberto Athayde. 2013. 200 f. Dissertação (Mestrado)

BORGES, R. Saberes em diálogo na prática filológica editorial 
Linha D'Água (Online), São Paulo, v. 31, n. 2, p. 7-27, maio-ago. 2018

- Instituto de Letras, Programa de Pós-Graduação em Literatura e Cultura, Universidade Federal da Bahia, Salvador, 2013.

CORREIA, Hugo Leonardo Pereira. Bemvindo Sequeira e a cena politica nas tramas de Me segura que eu vou dar um voto: edição e crítica filológica do texto teatral. 2014. 216 f. + DVD. Dissertação (Mestrado) - Instituto de Letras, Programa de Pós-Graduação em Literatura e Cultura, Universidade Federal da Bahia, Salvador, 2014.

GRÉSILLON, Almuth. Nos limites da Gênese: da escritura do texto de teatro à encenação. In: Estudos Avançados, 9 (23), Paris: ITEM, 1995, p. 269-285. Disponível em: <http://www.scielo. br/scielo.php?pid=S0103-40141995000100018\&script=sci_arttext $>$. Acesso em: 05 jun. 2010.

FAGUNDES, Carla Cecí Rocha. Edição e crítica filológica de Pau e Osso S/A do Amador Amadeu: o teatro amador em cena. 2014. 164 f. Dissertação (Mestrado) - Instituto de Letras, Programa de Pós-Graduação em Literatura e Cultura, Universidade Federal da Bahia, Salvador, 2014.

GRÉSILLON, Almuth. Elementos de crítica genética: ler os manuscritos modernos. Tradução Cristina de Campos Velho Birck et Al. Porto Alegre: Editora da UFRGS, 2007.

GRÉSILLON, Almuth. Crítica genética, prototexto, edição. Tradução Adriana Camargo. In: GRANDO, Ângela; CIRILLO, José (Org.). Arqueologias da criação: estudos sobre o processo de criação. Belo Horizonte: C/Arte, 2009. p. 41-51.

GUZMÁN GUERRA, Antonio; TEJADA CALLER, Paloma. ¿Cómo estudiar filología?. Madrid: Alianza, 2000.

HAY, Louis. L'Ancien et le Nouveu Monde: L'edition du texte. In: LITTERATURE LATINO -AMERICAINE ET DES CARAIBES DU XX SIECLE: theorie et pratique de l'edition critique. Roma: Bulzoni, 1988. p. 87-102. (Collection Archives). Seminaire a la Bibliotheque Nationale de Paris - Mai 1984.

JESUS, Ludmila Antunes de. A Dramaturgia de João Augusto: edição crítica de textos produzidos na época da ditadura militar. 2008. 202 f. Dissertação (Mestrado em Letras em Linguística) Instituto de Letras, Universidade Federal da Bahia, 2008. 
Linha D'Água (Online), São Paulo, v. 31, n. 2, p. 7-27, maio-ago. 2018

JESUS, L. A. Teatro de cordel de João Augusto entre arquivo(s), edição e estudos. 2014.177 f. + DVD. Tese (Doutorado) - Instituto de Letras, Programa de Pós-graduação em Literatura e Cultura, Universidade Federal da Bahia, Salvador, 2014.

LIMA, Liliam Carine da Silva. Manual de construção, a arquitetura poética de João Augusto: edição genética e estudo crítico. 2014. 207f. Dissertação (Mestrado em Letras) - Instituto de Letras, Universidade Federal da Bahia, 2014.

LOURENÇO, Isabel Maria da Graça. The William Blake Archive: da gravura iluminada à edição electrónica. 2009. 490 f. Tese (Doutorado em Letras) - Faculdade de Letras da Universidade de Coimbra, Programa de Pós-Graduação em Língua e literaturas Modernas, Coimbra. Disponível em:<www.dominiopublico.com.br>. Acesso em: 02 set. 2011.

MARQUILHAS, Rita. Filologia. In: CEIA, Carlos. (Org.). E-Dicionário de termos literários. Disponível em: <http://www2.fcsh.unl.pt/invest/edtl/index.htm>. Acesso em: 03 nov. 2010.

MATOS, Eduardo Silva Dantas de. Os manuscritos de Cândido ou O Otimismo - o herói de todo caráter, uma adaptação de Cleise Mendes: leituras do processo de criação e proposta de edição genética. 208f. Dissertação (Mestrado) - Instituto de Letras, Programa de Pós-Graduação em Literatura e Cultura, Universidade Federal da Bahia, Salvador, 2011.

MATOS, Eduardo Silva Dantas de. O manuscrito autógrafo e suas rasuras: autoria, subjetividade e edição. 2014. 202f. Tese (Doutorado) - Instituto de Letras, Programa de Pós-Graduação em Literatura e Cultura, Universidade Federal da Bahia, Salvador, 2014.

MCKENZIE, Donald Francis. Bibliografía y sociología de los textos. Tradução Fernando Bouza. Madrid: Akal, 2005.

MOTA, Mabel Meira. Da trama do arquivo à trama detetivesca de Irani ou As Interrogações, de Ariovaldo Matos: leitura filológica do arquivo e edição do texto. 2011. Dissertação (Mestrado) Instituto de Letras, Programa de Pós-Graduação em Literatura e Cultura, Universidade Federal da Bahia, Salvador, 2011.

MOTA, M. M. Filologia e Arquivística em tempos digitais: o arquivo hipertextual e as edições de $A$ Escolha ou O Desembestado de Ariovaldo Matos. 2017.234f. Tese (Doutorado) - Instituto de Letras, Programa de Pós-Graduação em Literatura e Cultura, Universidade Federal da Bahia, Salvador. 2017. 
Linha D'Água (Online), São Paulo, v. 31, n. 2, p. 7-27, maio-ago. 2018

PICCHIO, Luciana Stegagno. O Método filológico; comportamentos críticos e atitude filológica na interpretação de textos literários. In: . A Lição do texto; filologia e literatura; I Idade Média. Lisboa: Edições 70, 1979. p. 209-35.

SAID, Edward W. Humanismo e crítica democrática. Tradução Rosaura Eichenberg. São Paulo: Companhia das Letras, 2007.

SANTOS, R. B. (Org.). Edição e estudo de textos teatrais censurados na Babia: a Filologia em diálogo com a Literatura, a História e o Teatro. Salvador: EDUFBA, 2012

SANTOS, Rosa Borges dos. Uma metodologia aplicada à edição de textos teatrais. In: MAGALHÃES, José Sueli de e TRAVAGLIA, Luiz Carlos (Org). Múltiplas Perspectivas em Lingüistica. Uberlândia: Edufu, 2008.1 CD-ROM.

SOUZA, Arivaldo Sacramento de. Nas tramas de Greta Garbo, quem diria, acabou no Irajá: crítica filológica e estudo de sexualidades. 2014. 358 f. + DVD. Tese (Doutorado) - Instituto de Letras, Programa de Pós-Graduação em Letras e Linguística, Universidade Federal da Bahia, Salvador, 2014.

SOUZA, Débora de. Aprender a nada-r e Anatomia das feras, de Nivalda Costa: processo de construção dos textos e edição. 2012. 251 f. Dissertação (Mestrado) - Instituto de Letras, Programa de Pós-Graduação em Literatura e Cultura, Universidade Federal da Bahia, Salvador, 2012.

TELLES, Célia Marques; SANTOS, Rosa Borges dos. (Org.). Filologia, Críticas e Processos de Criação. Curitiba: Appris, 2012.

URBINA, E. et al. Humanidades digitales, crítica textual y la edición variorum electrónica del Quijote (EVE DQ). AISPI. Actas XXIII (2005). p. 223-235. Disponível em: <http://cvc.cervantes.es/literatura/aispi/pdf/21/I_20.pdf>. Acesso em: 02 set. 2011.

Recebido: 20/05/2018

Aprovado: 19/6/2018

BORGES, R. Saberes em diálogo na prática filológica editorial 